\title{
O ENSINO DO HANDEBOL NA CATEGORIA INFANTIL A PARTIR DOS DISCURSOS DE TREINADORES EXPERIENTES
}

\author{
HANDBALL TEACHING IN UNDER-14 TEAMS ACCORDING TO \\ EXPERIENCED COACHES' DISCOURSES
}

\author{
LA ENSEÑANZA DEL BALONMANO EN LA CATEGORÍA INFANTIL \\ A PARTIR DE LOS DISCURSOS DE ENTRENADORES EXPERTOS \\ Rafael Pombo Menezes*, Renato Francisco Rodrigues Marques*, \\ Myrian Nunomura*
}

Palavras-chave

Ensino.

Esportes.

Handebol.

Criança.

Keywords:

Teaching.

Sports.

Handball.

Child.

Palabras clave

Enseñanza.

Deportes.

Balonmano.

Niño.
Resumo: 0 objetivo deste estudo foi mapear os métodos de ensino adotados por seis treinadores de handebol experientes da categoria infantil (sub-14). Os treinadores foram entrevistados e os depoimentos tabulados e analisados de acordo com o método do Discurso do Sujeito Coletivo. Os resultados apontam que os treinadores preferem 0 ensino por meio de jogos, também mencionam o ensino baseado nas situações do jogo, nas habilidades técnicas e na combinação de diferentes métodos (devido à diversidade de estímulos e desenvolvimento de capacidades diferentes). Conclui-se que os procedimentos pedagógicos estão pautados na formação generalista, e evitam o processo de especialização esportiva precoce.

Abstract: The aim of this study was to map teaching methods adopted by six experienced under-14 handball coaches. They were interviewed and the speeches were tabulated and analyzed according the method of Collective Subject Discourse. Results indicate that coaches prefer teaching through games. They also referred to teaching based on game situations, technical skills and combination of different methods (due to the diversity of stimuli and the development of different abilities and skills). The findings suggest that coaches' procedures are guided by generalist training and avoid the process of early sport specialization.

Resumen: El objetivo de este trabajo fue identificar los métodos de enseñanza adoptados por seis entrenadores expertos de balonmano en equipos infantiles. Los entrenadores fueron entrevistados y las declaraciones tabuladas y analizadas de acuerdo con el método del Discurso del Sujeto Colectivo. Los resultados indican que los entrenadores prefieren la enseñanza a través de juegos y mencionan la enseñanza basada en situaciones de juego, habilidades técnicas y en la combinación de diferentes métodos (justificado por la diversidad de estímulos y el desarrollo de diferentes capacidades). Así, los procedimientos de enseñanza se orientan por el proceso de formación general, evitando la especialización deportiva temprana.
*Universidade de São Paulo (USP). Ribeirão Preto, SP, Brasil. E-mail: rafaelpombo@usp.br

Recebido em: 05-06-2014 Aprovado em: 12-02-2015 (c) (1) (8) Licence 


\section{INTRODUÇÃO}

Os aspectos distintos e pertinentes ao processo de ensino-aprendizagemtreinamento ${ }^{1}$ (EAT) e aos procedimentos utilizados para a abordagem dos elementos específicos dos esportes são objetos de estudo relevantes no campo da Pedagogia do Esporte (SCHMIDT-MILLARD, 2003). A Pedagogia do Esporte também abrange o estudo dos aspectos educacionais em diferentes âmbitos a partir da apropriação das práticas corporais no e pelo esporte (REVERDITO; SCAGLIA; PAES, 2009).

Além disso, a Pedagogia do Esporte preocupa-se com a formação dos profissionais envolvidos na gestão e no desenvolvimento do processo de EAT, principalmente com a compreensão que eles possuem das características que cercam esse processo, como 0 domínio dos métodos de ensino (e não apenas a repetição de procedimentos vivenciados como atleta) e a importância do aluno como elemento central nesse contexto (EGERLAND; NASCIMENTO; BOTH, 2009, NUNOMURA; CARBINATTO; CARRARA, 2013, MENEZES; MARQUES; NUNOMURA, 2014, REVERDITO; SCAGLIA; PAES, 2009). Não obstante, as discussões sobre os métodos mais eficazes para o ensino de jogos esportivos coletivos (JEC), com polaridade destacada para a ênfase nos elementos técnicos ou táticos, têm sido objeto de preocupação entre diversos autores da área (GRÉHAIGNE; GODBOUT, 1995, GARCÍA HERRERO; RUIZ PÉREZ, 2003, PÉREZ MORALES; GRECO, 2007, MESQUITA; PEREIRA; GRAÇA, 2009, SILVA; GRECO, 2009).

O handebol é caracterizado como um JEC de invasão e apresenta ambiente complexo no qual os jogadores devem utilizar elementos técnicos e táticos diferentes para alcançar seus respectivos objetivos, como anotar um gol ou impedir que 0 adversário 0 anote. Diante desse cenário emergem as relações de oposição e de cooperação entre os jogadores (GARGANTA, 1998) que estão presentes desde as etapas iniciais até 0 treinamento de alto rendimento (EHRET et al., 2002).

A categoria infantil do handebol engloba jogadores com idades entre 13 e 14 anos, e é considerada a fase de transição entre as etapas de formação e de decisão (próxima à especialização) (GRECO; SILVA; GRECO, 2012). Para Ehret et al. (2002) essa etapa é denominada de treinamento básico, que precede a fase de treinamento de formação (iniciado na categoria cadete, com jogadores de 15 e 16 anos de idade) e sucede a etapa de formação básica (encerrada na categoria mirim, com jogadores de 11 e 12 anos de idade). Baratti e Casali (2008) apontam que na categoria infantil o handebol pode ser trabalhado de forma específica, porém, sem a orientação para o processo de especialização.

$\mathrm{Na}$ categoria infantil, ressaltamos que o regulamento de algumas competições ${ }^{2}$ pode apresentar exigências abordadas na categoria mirim (que engloba jogadores de 11

1 Neste estudo será considerada a tríade ensino-aprendizagem-treinamento (EAT) a partir da proposta de Greco (1995), cuja compreensão se dá no sentido de que o ensino e a aprendizagem são consolidados a partir do treinamento, e que este não necessariamente remonta à especialização esportiva, mas à prática e às vivências (assim como apontado por Galatti, Paes e Darido (2010), que denominam tal processo de "ensino, vivência e aprendizagem").

2 Os regulamentos de diferentes instituições ligadas ao handebol foram consultados, tais como: a) Confederação Brasileira de Handebol (CBHb), disponível em http://www.brasilhandebol.com.br/Admin/Anexos/000490 Regulamento\%20Geral\%20de\%20 Competi\%C3\%A7\%C3\%B5es\%202013.pdf (onde não constam as questões relacionadas à utilização dos sistemas defensivos) e http://cbhb. com.br/Admin/Anexos/000598 REGULAMENTO \%20CB\%20INFANTIL\%20DE\%20CLUBES\%202013.pdf (onde constam as mudanças entre os sistemas defensivos); b) Federação Paulista de Handebol (FPH), disponível em http://www.fphand.com.br/images/ stories/regulamento menores 2012.pdf (consta o regulamento de 2012, cujo tempo de jogo é estipulado em dois períodos de 25 minutos); c) Liga de Handebol do Estado de São Paulo (LHESP), disponível em http://www.Ihesp.com.br/anexos/Regulamento_2014.pdf (no qual constam as mudanças de 
e 12 anos de idade), como a obrigatoriedade da marcação individual durante determinado período de tempo, bem como prever elementos referentes à categoria subsequente (cadete, composta por jogadores de 15 e 16 anos), na qual é permitida a utilização de sistemas defensivos zonais durante todo o jogo. Desta maneira, em algumas competições o jogo é constituído de dois períodos de 20 minutos de duração, sendo que nos dez minutos iniciais de cada um desses a utilização do sistema defensivo individual é obrigatória que poderá ser ou não mantida durante os dez minutos finais de cada período.

Por se tratar de uma etapa intermediária entre a iniciação ao handebol e o treinamento especializado (EHRET et al., 2002), cujos regulamentos das competições privilegiam o desenvolvimento de características individuais e coletivas dos jogadores, é necessário atentar para o papel desempenhado pelos treinadores. 0 aperfeiçoamento técnico e tático de seus jogadores é competência do treinador esportivo (MELLO; COZAC, 2013), assim como a atribuição de valor e significado à competição e à formação de jovens jogadores que sejam capazes de tomar decisões inteligentes no cenário técnico-tático (MATIAS; GRECO, 2010, RAMOS et al., 2011). Assim, tornam-se relevantes estudos que busquem o mapeamento de variáveis técnico-táticas no âmbito de treinamento.

Canciglieri et al. (2008) entrevistaram sete treinadores de basquetebol para mapear os métodos aplicados para o treinamento dos pivôs e identificaram a confusão e o desconhecimento dos treinadores sobre conceitos como a técnica esportiva. Milistetd et al. (2009) entrevistaram dez treinadores de voleibol para analisar os requisitos de especialização funcional na formação (de longo prazo) de jogadores da modalidade. Os autores apontam que os treinadores entrevistados apresentam pluralidade de ideias quando o tema central é a especialização das funções dos jogadores, e não há consenso sobre a idade ideal para iniciar o processo de especialização por posição de jogo (posto específico).

Ramos et al. (2011) entrevistaram quatro treinadores de basquetebol (com mais de dez anos de experiência) cujo objetivo era compreender a forma com que aprenderam a profissão. Os autores revelaram que há grande valorização do conhecimento prático (ou de resolução de problemas) pelos treinadores e que os propósitos de treino, muitas vezes, são influenciados por suas experiências pessoais.

Considerando o cenário complexo do jogo e das atribuições dos treinadores, tornam-se importantes estudos que busquem compreender os procedimentos pedagógicos adotados pelos treinadores para a formação dos jogadores, assim como a forma de lidar com o processo de EAT. A partir dos estudos apresentados anteriormente com diferentes JEC, notam-se temáticas emergentes e específicas para cada esporte.

Métodos de ensino diferentes de JEC podem ser utilizados para oportunizar as vivências no handebol aos jogadores, dentre os quais destacamos: a) analítico-sintético, cuja ênfase debruça-se sobre os elementos técnicos desvinculados da tática; b) global-funcional, relacionado com o ensino por meio de jogos de complexidades variadas; $c$ ) situacional, o qual se baseia em unidades funcionais extraídas do próprio jogo que culminam em situações reduzidas (GRECO, 2001, MENEZES; MARQUES; NUNOMURA, 2014). 
Assim, as perguntas motivadoras para o desenvolvimento deste estudo foram as seguintes: "quais são os métodos de ensino utilizados por treinadores experientes no ensino do handebol para a categoria infantil?"; e "quais são as suas justificativas para a utilização de cada método de ensino dos JEC?". Para tanto, parte-se da hipótese inicial de que o processo de EAT ocorre de forma plural a partir do oferecimento de estímulos variados aos jogadores, de modo que Ihes possibilite compreender 0 handebol em sua totalidade, ou seja, os elementos técnicos, técnico-táticos e os sistemas de jogo. Diante desse panorama, o objetivo deste estudo foi apontar e discutir os métodos de ensino utilizados na categoria infantil do handebol a partir dos discursos de treinadores experientes.

\section{METODOLOGIA}

Participaram da amostra seis treinadores do Estado de São Paulo vinculados a equipes representativas municipais (todos graduados em Educação Física, aqui denominados S1, S2, S3, S4, S5, S6), considerados experientes (média de idade de $42,7 \pm 6,4$ anos e tempo de atuação como treinador de $18 \pm 5,9$ anos), com resultados expressivos na principal competição do Estado (três primeiras colocações, na primeira e segunda divisões). Os treinadores assinaram um Termo de Consentimento Livre e Esclarecido, aprovado previamente por um Comitê de Ética em Pesquisa institucional, garantindo o sigilo de suas informações pessoais e o uso exclusivo das informações para fins acadêmicos.

O acesso ao pensamento humano é um argumento importante para a essência da pesquisa qualitativa, cuja exteriorização a partir da consciência humana é possível de ser recuperada (LEFĖVRE; LEFĖVRE, 2003). Devido à natureza discursiva dos dados, os depoimentos foram transcritos, tabulados e analisados de acordo com o método do Discurso do Sujeito Coletivo (LEFÈVRE; LEFÈVRE, 2003; 2012), que parte de perguntas abertas de caráter discursivo com os sujeitos analisados, das quais se pretende identificar as informações sobre os pensamentos e as opiniões desses sobre determinado assunto (LEFÈVRE; LEFÈVRE, 2003). Esses pensamentos podem não ser explícitos por pesquisas quantitativas ou de observação (MARCONI; LAKATOS, 2011). Há a preocupação com o nível de realidade que não pode ser quantificado e está repleto de sentidos, significados, crenças e valores (MARCONI; LAKATOS, 2011).

O DSC preserva a natureza discursiva das opiniões, assim como o compartilhamento de opiniões semelhantes que podem ser reunidas em único discurso-síntese. Pressupõese que os indivíduos que fazem parte de determinado grupo social não compartilham, necessariamente, ideias semelhantes, e o fato poderia gerar divergências sobre determinados preceitos e procedimentos.

Desta maneira, o DSC revela diferentes categorias de pensamento na amostra estudada, ainda que discorra-se sobre o mesmo tema e configure discursos distintos (DSC) com rótulos próprios. É possível identificar e reconstruir ideias semelhantes a partir de uma base indutiva diante de um conjunto de discursos individuais, no qual cada DSC reúne e articula os diferentes argumentos de determinada opinião. $O$ fato preserva 
o discurso do pensamento coletivo desde a elaboração das perguntas até culminar com a apresentação dos resultados.

O objetivo é expressar o pensamento de uma comunidade/coletividade pela agregação de trechos isolados dos discursos individuais, nos quais são mantidas a coerência e a constituição de cada uma das partes que o compõem (LEFÈVRE; LEFÈVRE, 2003, SANTANA, 2008). Para isso, três figuras metodológicas são importantes no método do DSC: a) as expressões-chave (ECH): transcrições literais de trechos do discurso que revelam a essência do depoimento a partir dos segmentos nos quais esse se divide; b) as ideias centrais (IC), que são a descrição sucinta, fidedigna e objetiva do sentido de determinado discurso sobre a temática, de modo a reduzir a polissemia dos discursos; $\mathrm{c}$ ) o próprio Discurso do Sujeito Coletivo (DSC), que consiste na elaboração de um discurso, em primeira pessoa, a partir do conjunto de ECH que possuam a mesma IC (LEFÈVRE; LEFÈVRE, 2003).

Assim, a partir de seus possíveis agrupamentos e reconstruções é possível expressar o discurso coletivo e não reduzir todos os discursos a uma categoria única, o que remeteria à quantificação simplista dos discursos (LEFÈVRE; LEFÈVRE, 2012). $\mathrm{Na}$ apresentação dos resultados serão expressas as IC captadas dos discursos (e os treinadores que mencionaram cada uma) e o DSC correspondente à cada IC. Autores como Santana (2008), Menezes (2011), Marques et al. (2013) utilizaram o mesmo método em estudos no âmbito esportivo para análise dos discursos de treinadores, dirigentes e atletas.

Os depoimentos dos treinadores foram coletados individualmente em local e data pré-agendados (não coincidentes com o horário de treinamento de suas equipes), a partir de um instrumento de entrevista semiestruturada (MARCONI; LAKATOS, 2011) cuja questão norteadora foi: "Como você acha que devem ser as atividades/exercícios na categoria infantil?'. A opção pela pesquisa qualitativa justifica-se pela tentativa de acessar informações de natureza descritiva, cuja atenção do pesquisador direciona-se aos significados atribuídos aos fatos e aos processos (não aos produtos) (TRIVIÑOS, 1987, SANTANA, 2008).

Para validação das declarações e evidências dos discursos dos participantes, após a transcrição dos áudios das entrevistas, o conteúdo foi enviado por e-mail para os sujeitos para conferência e eventuais modificações que se fizessem necessárias, não havendo nenhuma solicitação nesse sentido.

\section{RESULTADOS}

No Quadro 1 estão expressas as três IC captadas nos discursos (IC-1, IC-2 e IC-3), os respectivos treinadores que as mencionaram e os DSC correspondentes (DSC1, DSC2 e DSC3). 
Quadro 1 - IC e DSC correspondentes aos discursos dos treinadores

\begin{tabular}{|c|c|}
\hline IC & DSC \\
\hline $\begin{array}{l}\text { IC-1: Prioridade em } \\
\text { oferecer jogos como } \\
\text { estratégia de ensino (S1, } \\
\text { S2, S4, S5, S6) }\end{array}$ & 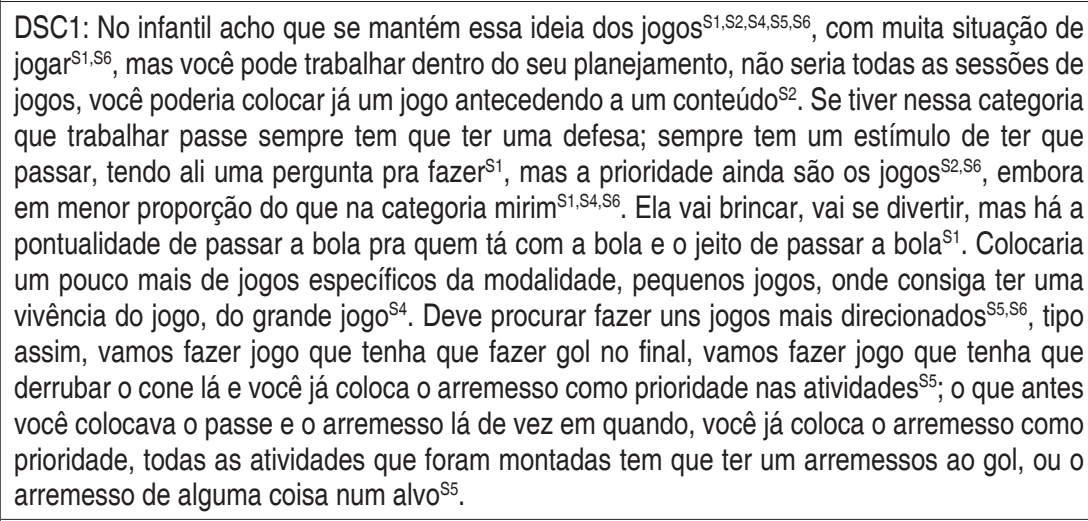 \\
\hline $\begin{array}{l}\text { IC-2: Preferência pela } \\
\text { utilização equilibrada } \\
\text { entre diferentes méto- } \\
\text { dos de ensino (S1, S2) }\end{array}$ & $\begin{array}{l}\text { DSC2: Eu não consigo ver o trabalho só com o jogo, porque o jogo não vai formar o especialista; } \\
\text { trabalhar só analítico você enfatiza a parte técnica, mas não trabalha uma concepção, um } \\
\text { conceito do jogo; e você tem as situaçães de jogo que você precisa trabalhar em cima delas, } \\
\text { então não tem como eu ficar em um sós2. Vão aparecer mais os exercícios dirigidos, de ataque } \\
\text { e de defesa; vão aparecer exercícios mais orientados pra arremessar, pra passar; vai aparecer } \\
\text { a situação de fila de 3, fila de 2, passe em colunas, pra poder ir consertando algumas coisas }{ }^{S 1} \text {. } \\
\text { Então trabalhar um jogo em cima do que você vai trabalhar naquela sua sessão de treino, mas } \\
\text { ele não é um exercício fechado, você vai trabalhar com vários exercícios combinados; se eu } \\
\text { vou trabalhar o passe, posso fazer exercícios combinados de passe com drible, ou um jogo } \\
\text { referente a aquilo de uma forma lúdica, ou um exercício combinado daquele conteúdos2. }\end{array}$ \\
\hline $\begin{array}{l}\text { IC-3: Preferência } \\
\text { pela utilização de } \\
\text { método ligado ao } \\
\text { desenvolvimento } \\
\text { técnico (S3, S4) }\end{array}$ & 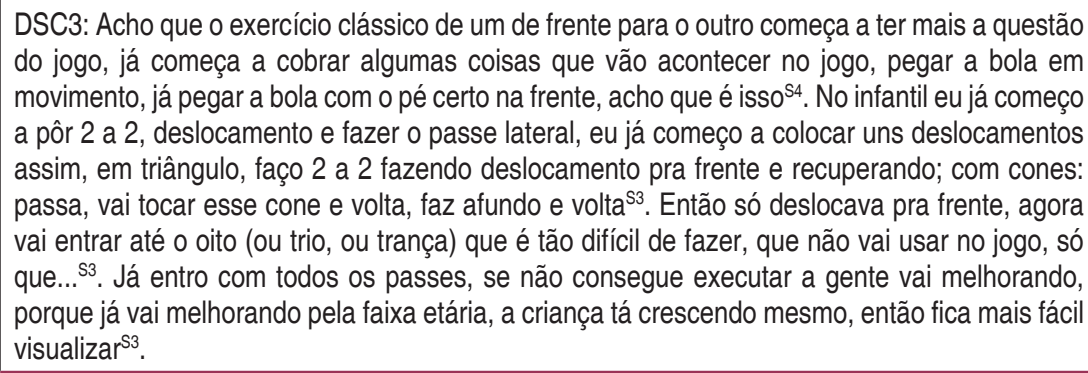 \\
\hline
\end{tabular}

Fonte: Dos autores

\section{DISCUSSÃO}

O ensino por meio de jogos apresenta posição de destaque na categoria infantil, conforme apontado no DSC1 (constituído por discursos da maioria dos treinadores - S1, S2, S4, S5 e S6), cujo relato destaca a importância e a relevância de métodos de aprendizagem ativa (HOPPER, 2002, PÉREZ MORALES; GRECO, 2007) nos quais os aprendizes são considerados o elemento central do processo de EAT. Nessa perspectiva os jogos são utilizados como meio para o ensino dos conteúdos do handebol que partem ou não da estrutura e dos elementos do jogo formal, mas que mantêm a complexidade do ambiente do jogo (DIETRICH; DURRWÄCHTER; SCHALLER, 1984, LEONARDO; SCAGLIA; REVERDITO, 2009, MENEZES; MARQUES; NUNOMURA, 2014) e suas invariantes, a saber: regras, bola, espaço de jogo, companheiros, adversários e alvo (BAYER, 1994).

No DSC1 os treinadores explicitam a importância dos jogos como elemento central para o ensino do handebol, que, por se tratar de forma ativa de aprendizagem, possuem forte apelo ao desenvolvimento tático e oportunizam a construção desse conhecimento pautado na diversidade de estímulos (PÉREZ MORALES; GRECO, 2007, LEONARDO; SCAGLIA; REVERDITO, 2009, SILVA; GRECO, 2009, MENEZES; MARQUES; NUNOMURA, 2014). 
Essa premissa contradiz o método analítico-sintético, abordado no DSC3, cujo objetivo é o desenvolvimento e 0 aprimoramento dos gestos técnicos específicos (o passe, 0 arremesso e a recepção no handebol) desvinculados do aprendizado tático, a partir da reprodução do modelo do alto rendimento.

De acordo com Ehret et al. (2002) os jogadores na categoria infantil devem jogar mais do que se exercitar de forma analítica e fragmentada (com base apenas na aprendizagem técnica), principalmente para contemplar a formação técnico-tática individual que abrange a compreensão do cenário dinâmico do jogo. 0 ambiente do jogo, dotado de incertezas e aspectos imprevisíveis, é passível de mudanças repentinas desencadeadas por comportamentos técnico-táticos dos jogadores dentro de uma aparente desordem, na qual as partes não podem ser compreendidas, e sequer têm sentido, de maneira fragmentada (GRECO, 2001, LEONARDO; SCAGLIA; REVERDITO, 2009, MENEZES, 2012). A complexidade desse cenário dinâmico exige comportamentos táticos flexíveis dos jogadores que lhes permitam adaptar-se rapidamente às imposições das situações-problema e possibilitar que as decisões sejam tomadas de forma inteligente (GRECO, 2001).

Entende-se que as interações entre os jogadores (expressas nas relações de cooperação e oposição) demandam grande flexibilidade do seu comportamento tático, notadamente das capacidades de percepção, atenção, antecipação e tomada de decisão (MATIAS; GRECO, 2010). Ehret et al. (2002) apontam que não se deve limitar taticamente os jogadores, mas priorizar o jogo criativo de forma livre por meio de diferentes apropriações do espaço de jogo, de diferentes alvos e de relações numéricas entre atacantes e defensores. Essas premissas são contempladas pelo ensino por meio de jogos nos quais as alterações nos parâmetros invariantes podem beneficiar o aprendizado de determinados conteúdos.

Explana-se no DSC1 sobre a importância dos jogos para a manutenção da relação de oposição e, ao mesmo tempo, para a reprodução de dinâmicas semelhantes àquelas encontradas no jogo formal, notadamente, a partir das diferentes fases do jogo (ofensiva, defensiva e transições). Diante desse contexto, Garganta (1998) destaca que a relação de cooperação permite que os jogadores manifestem suas capacidades individuais de modo a priorizar os interesses da equipe. Ainda, a manutenção da estrutura de jogo entre atacantes e defensores passa a ser imprescindível, pois perpassa pela relevância de abordar os princípios ofensivos e defensivos dos JEC, dos quais destacam-se: a conservação da posse da bola, a progressão em direção ao alvo adversário, a manutenção da complexidade do jogo e a finalização na meta (princípios ofensivos); a recuperação da posse da bola, o impedimento da progressão do adversário e a proteção da meta (princípios defensivos) (BAYER, 1994; GRÉHAIGNE; GODBOUT, 1995).

Embora os treinadores entrevistados apontem a importância da utilização dos jogos no processo de EAT da categoria infantil, eles afirmam que esse panorama ocorre em proporção inferior ao da categoria mirim, assim como apontado por Antón García (1990). A formação por meio de jogos volta-se para o desenvolvimento da capacidade do jogador de resolver as situações-problema impostas pelo cenário técnico-tático, assim os treinadores evidenciam sua maior preocupação com a eficácia dos gestos técnicos (cuja execução contempla os requisitos estratégico-táticos) em relação à sua eficiência (referente à execução de um movimento com a maior precisão e o mínimo gasto energético). Ainda assim, é possível apresentar as vantagens do método situacional que, pelo fato das atividades 
serem desenvolvidas em situações mais simples que permitem o trabalho tático com maior especificidade, também possibilitam maior atenção aos gestos técnicos solicitados no contexto de jogo (e sem estereótipo definido).

No DSC2 os treinadores (S1, S2) apontam a necessidade de diversificar os métodos de ensino aplicados, que propiciem aos jogadores a formação variada e que contemple tanto os aspectos táticos como os técnicos. Os argumentos apresentados por esses treinadores explicitam a sua preocupação com a continuidade da prática pelos jogadores envolvidos, pois a apresentação de diferentes estímulos na abordagem de determinado conteúdo e fomentados por diferentes métodos de ensino transformam o ambiente de ensino em espaço motivador e desafiador (SANTANA, 2005).

A preocupação com o engajamento duradouro dos jovens na prática é um ponto que merece destaque no discurso dos entrevistados. Processos de formação esportiva tradicionais baseiam-se, principalmente, em duas perspectivas: a especialização precoce e a tríade "iniciação, especialização, alto rendimento". Porém, em ambas as perspectivas, sujeitos que não conseguem obter destaque em algumas das etapas correm o risco de ser excluídos do processo de desenvolvimento esportivo. Nesse sentido, a preocupação dos treinadores em diversificar práticas e formar praticantes que compreendam o sentido do jogo, sendo autônomos frente aos problemas apresentados, é uma forma de desenvolver a cultura esportiva, de modo que, mesmo que os envolvidos não alcancem o alto rendimento, mantenham-se engajados na idade adulta (MENEZES; MARQUES; NUNOMURA, 2014).

Essa perspectiva encontra ressonância na literatura, por exemplo, no Modelo de Desenvolvimento de Participação Esportiva (DMSP - sigla em inglês), que propõe três trajetórias de formação diferentes dessa cultura esportiva em longo prazo (CÔTĖ; BAKER; ABERNETHY, 2007): a) práticas variadas durante a iniciação e continuidade em participações recreativas no decorrer da vida resultam na participação no esporte como conteúdo de lazer; b) mesmas práticas iniciais da anterior, mas com um processo de especialização esportiva após a puberdade, resultam na participação no alto rendimento ou lazer; c) especialização esportiva precoce.

Os treinadores apontam algumas fragilidades ao optar por apenas um método de ensino ao longo do processo de formação dos jogadores (DSC2). 0 primeiro ponto destacado refere-se ao fato de que apenas o ensino por meio de jogos não seria suficiente para formar posteriormente um jogador especialista em determinado posto específico. Em contrapartida, os treinadores também apontam o método analítico-sintético como insuficiente para a compreensão do jogo, visto que os exercícios desse método tratam os conteúdos de forma isolada do contexto de jogo com ênfase no aprimoramento da técnica (GRECO, 2001; MENEZES; MARQUES; NUNOMURA, 2014).

Há alusão ao método situacional (ainda no DSC2), assim como aos demais métodos, com a premissa de trabalhar especificamente determinados conteúdos. Os treinadores ( $S 1$, S2) destacam que determinado conteúdo poderia ser trabalhado por estímulos variados proporcionados pelos princípios dos diferentes métodos de ensino, de modo que a ênfase possa ser sobre a qualidade (eficiência) do movimento, à sua efetividade no ambiente de jogo ou ainda à resolução de situações-problema. Assim, o ambiente complexo promovido pelos diferentes jogos permitiria o desenvolvimento concomitante de uma técnica eficaz para a situação-problema imposta (HOPPER, 2002). 
García Herrero e Ruiz Pérez (2003) indicam que o desenvolvimento eficaz do jogador no esporte perpassa pelo bom domínio das habilidades técnicas específicas e pelo seu conhecimento tático, e sugerem que o maior conhecimento do esporte poderia ser fomentado se ambos (domínio técnico e tático) fossem orientados pela intenção tática. Com base nos seus resultados, os autores apontam que os jogadores que treinaram a partir da orientação tática desenvolveram maior conhecimento declarativo quando comparados com aqueles que tiveram apenas orientação técnica.

É importante ressaltar que cada método pode contribuir diferentemente para a formação do jogador, seja a partir do aprimoramento dos elementos técnicos ou da problematização do contexto técnico-tático do handebol em forma de jogos ou de situações reduzidas. Nessa perspectiva, devemos considerar o incremento do repertório de decisões dos jogadores de maneira intencional a partir de métodos que se utilizam dos jogos e das situações reduzidas do jogo formal (MENEZES; MARQUES; NUNOMURA, 2014).

No DSC3 os treinadores (S3, S4) citam a necessidade de aprimoramento dos elementos técnicos (fundamentos), principalmente do passe e da recepção, a partir de exercícios analíticos que se originam da fragmentação de cada técnica. Os treinadores justificam a opção por utilizar o método analítico devido à faixa etária e acreditam que haja a tendência de melhoria técnica apenas relacionada a esse fator. Malina, Bouchard e Bar-Or (2009) apontam que nesse período há aumento na velocidade de crescimento em meninos e em meninas decorrente da acentuação do processo de maturação. 0 crescimento rápido das extremidades do corpo de indivíduos em período puberal pode acarretar em movimentos menos coordenados, o que contraria a justificativa apontada no DSC3 de que a faixa etária, por si só, seria responsável pela melhoria da qualidade técnica. Entendemos, ainda, que há a necessidade de diversificar os estímulos nessa faixa etária, principalmente referentes às vivências dos jogos para que os jogadores possam desenvolver seu repertório de soluções e de movimentos.

Greco, Silva e Greco (2012) citam que nessa faixa etária deve-se optar por não especializar os jogadores em determinadas posições de jogo (postos específicos), e que, ao sugerirem a formação plural, o treinamento técnico deveria ser conduzido de forma geral e priorizar o desenvolvimento das capacidades coordenativas com base em situaçõesproblema. Essa perspectiva corrobora o DMSP (CÔTĖ; BAKER; ABERNETHY, 2007), principalmente em relação ao questionamento da especialização esportiva precoce como modelo de sucesso para a formação de atletas de alto rendimento ou de praticantes no lazer.

Em relação à formação plural e à preocupação de nossos entrevistados quanto à manutenção do engajamento dos jogadores na prática, tem-se duas categorias importantes que, embora não mencionadas nos discursos, formam componente fundamental para processos de iniciação esportiva ligada à diversificação de experiências: a) brincadeiras ou jogos deliberados, definidos como atividades físicas intrinsecamente motivadoras "com gratificação imediata, especificamente designada para a máxima diversão" (CÔTÈ, 2013, p. 64); e b) práticas deliberadas, que são atividades estruturadas que requerem esforço "geralmente sem recompensas imediatas e motivadas pelo objetivo de melhora do desempenho e prazer pela prática" (FRASER-THOMAS; CÔTĖ; DEAKIN, 2008, p. 319). Outras características da prática deliberada são as regras explícitas, o envolvimento geralmente requisitado de adultos e as instalações físicas adequadas (CÔTĖ; BAKER; ABERNETHY, 2007). 
Côtè (2013) aponta que a iniciação esportiva diversificada é composta de grande carga de jogos deliberados e pequena de práticas deliberadas. No decorrer do processo de formação esportiva, com a entrada na fase de especialização ou investimento, por exemplo, inicia-se a inversão dessa oferta, com o aumento das práticas deliberadas até a chegada ao alto rendimento com a diminuição gradativa dos jogos deliberados.

Desta maneira, o método situacional contempla o ensino da técnica sem desvinculála da tática. A aprendizagem de ambos os aspectos poderia ocorrer de forma concomitante (GRECO, 2001), assim como a utilização do método global-funcional que englobe habilidades de outros JEC, premissas essas que contrariam a prioridade de utilização do método analíticosintético. Ehret et al. (2002) apontam que nessa etapa do desenvolvimento do jogador deve ser oferecida ampla gama de modalidades, para que o treinamento possa ser o mais variado possível e permita o desenvolvimento das capacidades coordenativas.

Apesar de se tratar de uma etapa na qual começa a aproximação ao treinamento especializado, devem ser preconizadas vivências variadas, como abordado por Ehret et al. (2002) quando apontam que todos os atacantes devem passar por todas as posições. Corroborando esses autores, Greco, Silva e Greco (2012) indicam que essa etapa marca o início do jogo posicional ofensivo que deve ser desenvolvido, prioritariamente, diante de diferentes sistemas defensivos. Porém, afirmar o emprego do método analítico nessa etapa como balizador (a partir de um modelo concebido no alto rendimento) pode parecer equivocado, pois muitos jogadores iniciam a prática do handebol nessa etapa ou na subsequente (categoria cadete) (MENEZES, 2010).

De maneira complementar, Greco, Silva e Greco (2012) sinalizam a importância do desenvolvimento da capacidade tática e técnica e, consequentemente, da inteligência tática, apoiada no método situacional. Para essa etapa, Antón García (1990) sugere como estratégias o desenvolvimento do jogo de conjunto, o incremento da exigência pela eficácia e as situações pedagógicas variadas, o que revela a importância do ensino por meio de jogos que contemplam os princípios operacionais ofensivos e defensivos (BAYER, 1994, GRÉHAIGNE; GODBOUT, 1995) e a ideia das transições ofensiva (quando se recupera a posse da bola) e defensiva (quando há a perda da posse da bola).

A formação generalista possibilita o desenvolvimento de capacidades distintas dos jogadores, de elementos técnico-táticos ofensivos e defensivos, dos conceitos de par e ímpar (GRECO; SILVA; GRECO, 2012), do entendimento desses conceitos no cenário técnico-tático do jogo e da continuidade do encadeamento das ações ofensivas (ANTÓN GARCÍA, 1990). A noção do conceito de par, ímpar e ataque ao intervalo se consolida a partir da compreensão dos atacantes sobre a utilização dos espaços da quadra diante da marcação individual, culminando na adequação de seus deslocamentos diante de diferentes sistemas defensivos que apresentam situações-problema específicas para os atacantes. Cabe ressaltar, ainda, a importância da utilização do sistema defensivo individual nessa categoria, pois permite o desenvolvimento de capacidades perceptivas, motoras e cognitivas dos jogadores tais como as mudanças de direção, os desmarques, a busca por linha de passe, a marcação e a continuidade do jogo ofensivo e defensivo.

Diante do exposto, duas posições foram observadas frente à questão norteadora do presente estudo: a primeira defende os jogos e a importância de se utilizar diferentes métodos (constituída por S1, S2, S4, S5 e S6), e a segunda defende a formação do jogador 
baseada apenas na automatização dos movimentos (destacado pelo S3). Essas posições, diametralmente opostas, indicam a ênfase nos diferentes procedimentos pedagógicos na categoria infantil que sugerem a formação generalista (destacada pela primeira posição) ou a formação especialista e remetem à especialização dos jogadores no handebol (sugerido pela segunda posição).

Destaca-se, assim, que a maioria dos treinadores entrevistados apoia o ensino pelos métodos que priorizam o desenvolvimento de capacidades envolvidas na resolução de problemas de forma intencional (enquanto apenas o S3 defende o ensino pautado no aspecto puramente técnico), seja por jogos ou situações específicas do handebol. Assim, diante dos achados na literatura que ressaltam os benefícios da utilização dos métodos global-funcional e situacional, a maioria dos treinadores entrevistados propõe que o processo de EAT seja pautado em atividades que privilegiem o desenvolvimento de capacidades táticas e técnicas interligadas, em detrimento do ensino técnico descontextualizado proposto por S3 sobre o método analítico-sintético.

Greco, Silva e Greco (2012) descrevem em linhas gerais que o processo de EAT deve buscar o desenvolvimento de capacidades como a percepção, a antecipação e a tomada de decisão que, dentre outras, constituem valências de um jogador inteligente (MATIAS; GRECO, 2010) e que proporcionam a formação generalista. Os treinadores entrevistados (com exceção de S3) parecem corroborar os apontamentos de Greco, Silva e Greco (2012), principalmente a partir dos desdobramentos possíveis no DSC2, que apontam para a formação mediada por métodos variados; e no DSC1, cuja ênfase está no ensino por meio de jogos associados à compreensão do cenário técnico-tático do handebol.

Métodos de ensino distintos podem ser empregados para possibilitar aos jogadores iniciantes o contato com os conteúdos do handebol, e que não necessariamente sejam especializados no próprio esporte ou em posições de jogo com premissas técnico-táticas específicas (MENEZES; MARQUES; NUNOMURA, 2014). Desta maneira, a variabilidade dos estímulos oferecidos aos jogadores visa ao desenvolvimento de diferentes capacidades por meio de experiências variadas em ambientes que agregam a complexidade das relações do jogo. Compreende-se, portanto, que os métodos de ensino priorizam o desenvolvimento de diferentes capacidades técnicas e técnico-táticas, que estão inter-relacionadas no complexo ambiente de jogo. É importante destacar a importância do estímulo e propostas de jogos e práticas deliberadas como forma de apoio pedagógico à formação esportiva diversificada $\mathrm{e}$ direcionada à compreensão da complexidade do jogo.

Assim, a opção pelo ensino por meio de jogos ou de situações reduzidas do jogo parece encontrar importante respaldo, tanto entre os treinadores entrevistados quanto na literatura consultada, ao passo que permite o desenvolvimento de diferentes capacidades relacionadas à resolução de problemas.

\section{CONCLUSÃO}

O handebol, como um JEC de invasão, apresenta características específicas e pode pautar-se por procedimentos pedagógicos diferentes daqueles que abordam esportes individuais. Dentre esses destacamos os jogos que problematizam o cenário técnico-tático do jogo configurado pelas relações de cooperação e oposição. As demandas impostas 
pela lógica do jogo e pela complexidade de seu ambiente sinalizam para procedimentos metodológicos que considerem tais aspectos, e que possibilitem a formação de jogadores que consigam tomar decisões intencionais diante das situações-problema apresentadas.

A crescente utilização de métodos de ensino ativos, apontado por diferentes autores, como é o caso do ensino por meio de jogos e a partir de situações extraídas do próprio jogo, também foi a opção confirmada pela maioria dos treinadores entrevistados neste estudo. As justificativas para a utilização do jogo como ferramenta de ensino são respaldadas por diversos autores (ANTÓN GARCÍA, 1990, DAOLIO; MARQUES, 2003, GARGANTA, 1998, GRECO, 2001, LEONARDO; SCAGLIA; REVERDITO, 2009, PÉREZ MORALES; GRECO, 2007, SILVA; GRECO, 2009) que apontam aspectos como a melhoria da criatividade e do pensamento tático dos jogadores, assim como a manutenção de um ambiente complexo, tal qual se apresenta o jogo de handebol. Essa opinião é corroborada neste estudo em face ao método analítico-sintético, cujas críticas envolvem o reducionismo do jogo aos seus elementos técnicos, a repetição exaustiva e a descontextualização da aplicação desses elementos (GRECO, 2001, MENEZES; MARQUES; NUNOMURA, 2014).

É importante que na categoria estudada (infantil) os procedimentos pedagógicos possibilitem aos jogadores estímulos variados pautando-se na formação generalista, na qual possam jogar em diferentes posições e em ambientes que sejam desafiadores. Desta maneira, entende-se que o método analítico, que prioriza o ensino fragmentado dos elementos técnicos do jogo, possa ser utilizado de forma coordenativa geral com vistas a evitar o processo de especialização precoce.

O presente estudo tentou contribuir com aspectos referentes à formação de jogadores de handebol na categoria infantil, a partir de entrevistas com treinadores experientes do Estado de São Paulo. Um dos aspectos que poderiam ser investigados, na perspectiva da Pedagogia do Esporte, refere-se à falta de uniformidade entre os regulamentos das diferentes instituições que organizam o handebol no cenário nacional, o que impõe barreiras para o processo de EAT na categoria infantil.

Uma limitação do estudo foi a análise do cenário do ensino do handebol no Estado de São Paulo, que não reflete a totalidade do cenário nacional. Uma possibilidade de ampliação deste trabalho seria a realização destas entrevistas com treinadores de outras regiões do Brasil e/ou de equipes masculinas.

Como possibilidade de estudos futuros, pode-se também apontar a observação sistemática das sessões de treinamento, de modo a complementar a análise de discurso dos treinadores e aproximar suas descrições com aquilo que vem ocorrendo nas sessões práticas.

\section{REFERÊNCIAS}

ANTÓN GARCÍA, Juan Oliver. Balonmano: fundamentos y etapas de aprendizaje. Madrid: Gymnos Editorial, 1990.

BARATTI, Abel; CASALI, Eduardo. Balonmano: desarrollo de los fundamentos por medio de ejercitaciones y formas jugadas. Armenia: Kinesis, 2008. 
BAYER, Claude. 0 ensino dos desportos colectivos. Lisboa: Dinalivros, 1994.

CANCIGLIERI, Paulo Henrique et al. Características e funções dos pivôs no basquetebol: análises e reflexões a partir de relatos de técnicos brasileiros. Revista Mackenzie de Educação Física e Esporte, São Paulo, v. 7, n. 3, p. 97-102, 2008.

CÔTĖ, Jean; BAKER, Joseph; ABERNETHY, Bruce. Practice and play in the development of sport expertise. In: EKLUND, R.; TENENBAUM, G. (Ed.). Handbook of sport psychology. 3. ed. Hoboken: Wiley, 2007. p. 184-202.

CÔTĖ, Jean. Pathways to expertise in team sport. In: NASCIMENTO, J. V. do; RAMOS, V.; TAVARES, F. (Org.). Jogos desportivos: formação e investigação. Florianópolis: UDESC, 2013. p. 59-78.

DAOLIO, Jocimar; MARQUES, Renato Francisco Rodrigues. Relato de experiência com o ensino de futsal para crianças de 9 a 12 anos. Motriz, Rio Claro, v. 9, n. 3, p. 169-174, 2003.

DIETRICH, Knut; DÜRRWÄCHTER, Gerhard; SCHALLER, Hans-Jürgen. Os grandes jogos: metodologia e prática. Rio de Janeiro: Ao livro técnico, 1984.

EGERLAND, Ema Maria; NASCIMENTO, Juarez Vieira do; BOTH, Jorge. As competências profissionais de treinadores esportivos catarinenses. Motriz, Rio Claro, v. 15, n. 4, p. 890-899, 2009.

EHRET, Arno et al. Manual de handebol: treinamento de base para crianças e adolescentes. São Paulo: Phorte, 2002.

FRASER-THOMAS, Jessica; CÔTĖ, Jean; DEAKIN, Janice. Examining adolescent sport dropout and prolonged engagement from a developmental perspective. Journal of Applied Sport Psychology, Philadelphia, v. 20, n. 3, p. 318-333, 2008.

GALATTI, Larissa Rafaela; PAES, Roberto Rodrigues; DARIDO; Suraya Cristina. Pedagogia do esporte: livro didático aplicado aos jogos esportivos coletivos. Motriz, Rio Claro, v. 16, n. 3, p. 751-761, 2010.

GARCÍA HERRERO, Juan Antonio; RUIZ PÉREZ, Luis Miguel. Análisis comparativo de dos modelos de intervención en el aprendizaje del balonmano. Revista de Psicología del Deporte, Barcelona, v. 12, n. 1, p. 55-66, 2003.

GARGANTA, Júlio. 0 ensino dos jogos desportivos. 3. ed. Porto: Centro de Estudos dos Jogos Desportivos, Universidade do Porto, 1998.

GRECO, Pablo Juan. $O$ ensino do comportamento tático nos jogos esportivos coletivos: aplicação no handebol. 1995. 224f. Tese (Doutorado) - Faculdade de Educação, Universidade de Campinas, Campinas, 1995.

GRECO, Pablo Juan. Métodos de ensino-aprendizagem-treinamento nos jogos esportivos coletivos. In: GARCIA, E.; LEMOS, K. Temas atuais VI em educação física e esportes. Belo Horizonte: Saúde, 2001. Cap.3, p. 48-72.

GRECO, Pablo Juan; SILVA, Siomara Aparecida; GRECO, Fernando Lucas. O sistema de formação e treinamento esportivo no handebol brasileiro (SFTE-HB). In: GRECO, P. J.; FERNÁNDEZ ROMERO, J. J. (Org.). Manual de handebol: da iniciação ao alto nível. São Paulo: Phorte, 2012. Cap.17, p. 235-250. 
GRÉHAIGNE, Jean-Francis; GODBOUT, Paul. Tactical knowledge in team sports from a constructivist and cognitivist perspective. Quest, Florida, n. 47, p. 490-505, 1995.

HOPPER, Tim. Teaching games for understanding: the importance of student emphasis over content emphasis. Journal of Physical Education, Recreation and Dance, Reston, v. 73, n. 7, p. 44-48, 2002.

LEFÈVRE, Fernando; LEFĖVRE, Ana Maria Cavalcanti. Discurso do sujeito coletivo: um novo enfoque em pesquisa qualitativa. Caxias do Sul: EDUCS, 2003.

LEFÈVRE, Fernando; LEFÈVRE, Ana Maria Cavalcanti. Pesquisa de representação social: um enfoque qualiquantitativo: a metodologia do Discurso do Sujeito Coletivo. Brasília: Liber Livro, 2012.

LEONARDO, Lucas; SCAGLIA, Alcides José; REVERDITO, Riller Silva. O ensino dos esportes coletivos: metodologia pautada na família dos jogos. Motriz, Rio Claro, v. 15, n. 2, p. 236-246, 2009.

MALINA, Robert M.; BOUCHARD, Claude; BAR-OR, Oded. Crescimento, maturação e atividade física. 2. ed. São Paulo: Phorte, 2009.

MARCONI, Marina de Andrade; LAKATOS, Eva Maria. Metodologia científica. São Paulo: Atlas, 2011.

MARQUES, Renato Francisco Rodrigues et al. Mídia e o movimento paralímpico no Brasil: relações sob o ponto de vista de dirigentes do Comitê Paralímpico Brasileiro. Revista Brasileira de Educação Física e Esporte, São Paulo, v .27, n. 4, p. 583-596, 2013.

MATIAS, Cristino Julio; GRECO, Pablo Juan. Cognição e ação nos jogos esportivos coletivos. Ciências \& Cognição, Rio de Janeiro, v. 15, n. 1, p. 252-271, 2010.

MELLO, Daniel Donadio de; COZAC, João Ricardo Lebert. Importância da comunicação entre treinador e atleta. In: COZAC, J. R. L. Psicologia do esporte: atleta e ser humano em ação. Rio de Janeiro: Guanabara Koogan, 2013. p. 213-218.

MENEZES, Rafael Pombo. Contribuições da concepção dos fenômenos complexos para o ensino dos esportes coletivos. Motriz, Rio Claro, v. 18, n. 1, p. 34-41, 2012.

MENEZES, Rafael Pombo. O ensino dos sistemas defensivos do handebol: considerações metodológicas acerca da categoria cadete. Pensar a Prática, Goiânia, v. 13, n. 1, p. 1-16, 2010.

MENEZES, Rafael Pombo. Modelo de análise técnico-tática do jogo de handebol: necessidades, perspectivas e implicações de um modelo de interpretação das situações de jogo em tempo real. 2011. 303f. Tese (Doutorado) - Curso de Educação Física, Faculdade de Educação Física, Universidade de Campinas, Campinas, 2011.

MENEZES, Rafael Pombo; MARQUES, Renato Francisco Rodrigues; NUNOMURA, Myrian. Especialização esportiva precoce e o ensino dos jogos coletivos de invasão. Movimento, Porto Alegre, v. 20, n. 1, p. 351-373, 2014.

MESQUITA, Isabel Maria Ribeiro; PEREIRA, Felismina Rosa Marques; GRAÇA, Amândio Braga dos Santos. Modelos de ensino dos jogos desportivos: investigações e ilações para a prática. Motriz, Rio Claro, v. 15, n. 4, p. 944-954, 2009. 
de especialização funcional na formação desportiva a longo prazo do jogador de voleibol. Revista da Educação Física/UEM, Maringá, v. 20, n. 2, p. 161-170, 2009.

NUNOMURA, Myrian; CARBINATTO, Michele Viviene; CARRARA, Paulo Daniel Sabino. Reflexão sobre a formação profissional na ginástica artística. Pensar a Prática, Goiânia, v. 16, n. 2, p. 469-483, 2013.

PÉREZ MORALES, Juan Carlos; GRECO, Pablo Juan. A influência de diferentes metodologias de ensino-aprendizagem-treinamento no basquetebol sobre o nível de conhecimento tático processual. Revista Brasileira de Educação Física e Esporte, São Paulo, v. 21, n. 4, p. 291 299, 2007.

RAMOS, Valmor et al. A aprendizagem profissional - as representações de treinadores desportivos de jovens: quatro estudos de caso. Motriz, São Paulo, v. 17, n. 2, p. 280-291, 2011.

REVERDITO, Riller Silva; SCAGLIA, Alcides José; PAES, Roberto Rodrigues. Pedagogia do esporte: panorama e análise conceitual das principais abordagens. Motriz, Rio Claro, v. 15, n. 3 , p. 600-610, 2009.

SANTANA, Wilton Carlos de. Pedagogia do esporte na infância e complexidade. In: PAES, R.R.; BALBINO, H.F. Pedagogia do esporte: contextos e perspectivas. Rio de Janeiro: Guanabara Koogan, 2005. p. 1-24.

SANTANA, Wilton Carlos de. A visão estratégico-tática de técnicos campeões da Liga Nacional de Futsal. 2008. 260f. Tese (Doutorado) - Curso de Educação Física, Faculdade de Educação Física, Universidade de Campinas, Campinas, 2008.

SCHMIDT-MILLARD, Torsten. Perspectives of modern sports pedagogy. European Journal of Sport Science, Exeter, v. 3, n. 3, p. 1-8, 2003.

SILVA, Marcelo Vilhena; GRECO, Pablo Juan. A influência dos métodos de ensinoaprendizagem-treinamento no desenvolvimento da inteligência e criatividade tática em atletas de futsal. Revista Brasileira de Educação Física e Esporte, São Paulo, v.23, n. 3, p. 297-307, 2009.

TRIVIÑOS, Augusto Nibaldo Silva. Introdução à pesquisa em ciências sociais: a pesquisa qualitativa em educação. São Paulo: Atlas, 1987. 